\title{
Association Between Triglyceride Glucose Index and Risk of New-onset Diabetes Among Chinese Adults: Findings From the China Health and Retirement Longitudinal Study
}

\section{Chaolei Chen}

Guangdong Cardiovascular Institute

Lin Liu

Guangdong Cardiovascular Institute

Kenneth LO

Brown University

Jiayi HUANG

Guangdong Cardiovascular Institute

yuling Yu

Guangdong Cardiovascular Institute

yuqing HUANG

Guangdong Cardiovascular Institute

Feng Yingqing ( $D$ 651792209@qq.com )

Guangdong Cardiovascular Institute

\section{Research}

Keywords: Triglyceride glucose index, Diabetes mellitus, Association, CHARLS

Posted Date: September 23rd, 2020

DOI: https://doi.org/10.21203/rs.3.rs-80124/v1

License: (c) (i) This work is licensed under a Creative Commons Attribution 4.0 International License. Read Full License 


\section{Abstract}

\section{Background}

The triglyceride glucose (TyG) index has been proposed to be a simple surrogate of insulin resistance. We aimed to examine the relationship between TyG index and risk of incident diabetes in middle-age and elderly adults in China.

\section{Methods}

Nationally representative data from the China Health and Retirement Longitudinal Study 2011-2015 were used. Sociodemographic, medical, anthropometric, and laboratory information were collected following a standard protocol. Cox proportional hazards models and restricted cubic spline regression were performed to estimate hazard ratio (HR) with 95\% confidence interval (Cl) of diabetes for TyG index. Subgroup analyses were also conducted to examine potential interactions.

\section{Results}

Of 7428 participants without at baseline diabetes, 791 (10.6\%) participants developed diabetes over 3.4 years of follow-up. The multivariate HR for every SD increase in TyG index was 1.22 (95\% Cl, 1.14-1.31). When dividing TyG index into quartiles, the multivariate HRs for new-onset diabetes were 1.22 (0.96-1.54) for Q2, 1.61 (1.28-2.01) for Q3, and 1.73 (1.38-2.16) for Q4 (P for trend < 0.001) compared with Q1. The restricted cubic spline regression confirmed a linear association. No interaction was found between subgroup variables and association of TyG index with risk of diabetes.

\section{Conclusion}

TyG index was significantly and positively associated with risk of new-onset diabetes in middle-aged and elderly adults. TyG index may be a useful predictive marker for predicting new-onset diabetes.

\section{Introduction}

Diabetes is associated with increased risk of cardiovascular morbidity and all-cause mortality, imposing a huge public burden owing to its high prevalence [1]. In the past few decades, the number of adults with diabetes as well as the prevalent rate has considerably increased, especially in low and middle-income countries [2]. According to data from the International Diabetes Federation, China has the largest number of diabetic patients, which has reached 114.4 million in 2017, with a national rate of $10.9 \%$ [3]. Therefore, identifying individuals at high risk for developing diabetes is of major importance to reduce the incidence rate and related complications.

Insulin resistance (IR) is a major pathophysiological pathway of type 2 diabetes development and appears about two decades prior to the formal diagnosis $[4,5]$. A recent study indicated that IR was more closely associated with risk of incident diabetes than $\beta$-cell dysfunction, another pivotal pathological 
features of diabetes, among Chinese adults [6]. Additionally, in the past four decades, China has experienced disruptive transitions of dietary patterns and witnessed a massive rise in the number of individuals with obesity, which is major etiological factor for the diabetes epidemic by promoting the progression and severity of IR $[7,8]$. Thus, assessment of IR status is essential to prevent diabetes incidence. However, the traditional way to measure IR such as the homeostasis model assessment of IR (HOMA-IR) is time-consuming, complex, and costly for daily practice and in large epidemiological studies.

Recently, the triglyceride glucose (TyG) index, the product of triglyceride (TG) and fasting blood glucose (FBG), has attracted attention as a simple surrogate of IR owing to its good correlation with HOMA-IR and better performance for examining insulin sensitivity [9]. A few studies have examined the association of TyG index and diabetes in Asia and western populations [10-15]. However, the results were inconclusive and limited due to either the cross-sectional design [14], small sample size [12] or the geographically regional and selected population $[11,15]$. Therefore, we designed a prospective cohort study using nationally representative data from the China Health and Retirement Longitudinal Study (CHARLS) to explore the relationship between TyG index and risk of new-onset diabetes.

\section{Methods}

\section{Study design and participants}

Participants enrolled in this study were from the CHARLS, which is an ongoing longitudinal survey for accessing the social, economic and health status of community residents aged 45 years or older in China. Details of the study design of CHARLS have been described elsewhere [16]. Briefly, the CHARLS adopted a multistage probability sampling and investigated 17708 individuals in 28 provinces through random selection of 10257 households to cover the overall population in China in the first wave (W1, 2011-2012), making the sample nationally representative. The response rate was up to $81 \%$ in the baseline survey. Well-trained interviews collected sociodemographic, physical, biological, and healthrelated information of study participants complying with the standard study plan. To date, the follow-up surveys have been conducted twice, including the second wave (W2) in 2013 and the third wave (W3) in 2015. For the present study, 10111 individuals with laboratory measurement at W1 were initially enrolled. Participants aged less than 45y, missing TG, FBG, and glycated hemoglobin were excluded, leaving 9663 participants. Of those, 1760 with diabetes at baseline were further excluded. Next, we excluded subjects who died ( $n=103$ ) or lost follow-up ( $n=372)$ in the subsequent waves (W2 and W3) of the study. Finally, 7428 participants were enrolled for the final analysis (Figure 1). The Ethics Review Committee of Peking University approved CHARLS (IRB00001052-11015) and all participants gave informed consent before participation.

\section{Data collection and definitions}

After taking a rigorous training program, the researchers visited and interviewed participants in their homes using computer-assisted personal interview technology to collect sociodemographic information [including age, gender, education level (primary school or lower, secondary school, and higher), and 
marriage status (current married or not)], health behavior (including current smoking and drinking), medical history [including self-reported hypertension, diabetes, and cardiovascular disease (CVD)] and medication usage (including antihypertensive drugs, antidiabetic drugs, and lipid-lowering drugs).

Anthropometric indicators included systolic blood pressure (SBP), diastolic blood pressure (DBP), body mass index (BMI, calculated as weight in kilograms divided by the square of height in meters), and waist circumference (WC). Blood pressure were measured three times in a seated position by trained nurses using the HEM-7200 electronic monitor (Omron, Dalian, Japan). Hypertension was defined as SBP $\geq 140$ $\mathrm{mmHg}$ or DBP $\geq 90 \mathrm{mmHg}$ or self-reported prior diagnosis of hypertension by a doctor or using antihypertensive drugs in the past two weeks [17]. Height and WC were accurate to $0.1 \mathrm{~cm}$ and weight was accurate to $0.1 \mathrm{~kg}$.

For biomarkers assessment, the CHARLS researcher collected fasting blood samples from every participant. These samples were transported from all over the country to Beijing and were stored at minus $80^{\circ} \mathrm{C}$ at the Chinese Center for Disease Control and Prevention. The biological determination of FBG, Hemoglobin A1c, TG, total cholesterol (TC), low-density lipoprotein cholesterol (LDL-C), and high-density lipoprotein cholesterol (HDL-C) were conducted by professional staff. TyG index was calculated as In [TG $(\mathrm{mg} / \mathrm{dl}) \times \mathrm{FBG}(\mathrm{mg} / \mathrm{dl}) / 2$ ] [18]. At baseline and follow-up, diabetes was defined as FBG $>125 \mathrm{mg} / \mathrm{dL}$ or Hemoglobin A1c $>6.5 \%$ or self-reported prior diagnosis of hypertension by a doctor or using antidiabetic medications. Non-diabetic participants whose FBG was at 100-125 mg/dL or Hemoglobin A1c was at $5 \cdot 7-6 \cdot 4 \%$ were classified as having prediabetes [19]. Participants without diabetes and prediabetes were normoglycemic.

\section{Statistical Analysis}

Data were presented as mean standard deviation (SD) for continuous variables and percentage for categorical variables. Baseline characteristics between groups according to quartiles of TyG index (Q1, Q2, Q3, Q4) or developing diabetes or not were reported and compared using the One-Way ANOVA, Kruskal-Wallis $\mathrm{H}$ test and chi-square tests, as appropriate. We initially conducted Cox proportional hazards models to estimate HR with $95 \%$ confidence interval $(\mathrm{Cl})$ of diabetes for per SD increase as well as quartiles of TyG index. Three models were fitted. Model 1 was univariate. Models adjusted for age and gender. Fully adjusted model (Model 3) incorporated covariates including age, gender, education, marriage, smoking, drinking, BMI, WC, SBP, history of hypertension, history of CVD, and usage of lipidlowering drugs. Next, the shape of association between TyG index and incident diabetes was examined by multivariate adjusted Cox restricted cubic spline regression model. We choose three knots at quartiles 25th, 50th, and 75th. Finally, we conducted subgroup analyses (multivariate Cox proportional hazards models) including age ( $<65$ or $\geq 65$ years), gender (male or female), BMI ( $<25$ or $\geq 25 \mathrm{~kg} / \mathrm{m}^{2}$ ), and glycemic status (normoglycemia or prediabetes). $\mathrm{P}<0.05$ was considered statistically significant. $\mathrm{R}$ version 3.3.2 (R Foundation for Statistical Computing, Vienna, Austria) was used for all statistical analyses. 


\section{Results}

\section{Baseline characteristics of study participants}

The baseline characteristics of all the participants according to quartiles of TyG index and developing diabetes or not were summarized in Table 1 and Table 2, respectively. The present study included 7428 participants (male: $46.5 \%$ and mean age: 59.3 years). The mean value TyG index was 8.56. Among groups of TyG index quartiles, we observed significant differences in all baseline covariates except for marriage status and education level (Table 1). Compared with participants remaining non-diabetic during follow-up, subjects developed diabetes were older, having lower education level, less likely to be married, having higher levels of SBP, DBP, BMI, WC, TG, TC, LDL-C, HDL-C, FBG, Hemoglobin A1c, and TyG index, more likely to have hypertension and CVD, and more likely to use lipid-lowing drugs (Table 2).

\section{Hazard ratios for incident diabetes}

Over a median of 3.4 years of follow-up, 791 (10.6\%) participants developed diabetes. After controlling for age, gender, education, marriage, smoking, drinking, BMI, WC, SBP, history of hypertension, history of CVD, and usage of lipid-lowering drugs, every SD increase in TyG index was associated with $22 \%$ higher risk of developing diabetes (HR 1.22, 95\% Cl, 1.14-1.31). When dividing TyG index into quartiles, the multivariate HRs for new-onset diabetes were 1.22 (0.96-1.54) for Q2, 1.61 (1.28-2.01) for Q3, and 1.73 (1.38-2.16) for Q4 ( $P$ for trend < 0.001) (Table 3). In the restricted cubic spline regression models with full adjustment, the relationship between TyG index and risk of incident diabetes was linear (Figure 2).

\section{Subgroup analyses}

We performed subgroups analyses stratified by age gender, BMI and glycemic status, as provided in Table 4. No interaction was found between subgroup variables and association of TyG index with risk of diabetes. The positive relationship remained consistent in both men and women, younger and elderly participants, lean and overweight/obese participants, and normoglycemic and prediabetic participants (Table 4).

\section{Discussion}

We derived nationally representative data from the CHARLS and found an independent and positive relationship between the simple surrogate of IR (TyG index) and risk of new-onset diabetes in middleaged and elderly Chinese adults. Additionally, the effects of TyG index on diabetes were not interacted by age, gender, BMI and glycemic status. The associations between TyG index and incident diabetes were more pronounced in the elderly, women, individuals with obesity, and prediabetic subjects.

Our results were consistent with previous studies that indicated a linear relationship between TyG index and risk of diabetes. A recent study involving 4,285 middle-aged and elderly Korean adults with $\mathrm{BMI}<25$ $\mathrm{kg} / \mathrm{m}^{2}$ found a positive association of TyG index and diabetes after 12 years of follow-up. Similarly, in 
lean Chinese individuals, Zhang et al. suggested that TyG index was predictive of incident diabetes. The authors claimed that lean people were more likely to be comorbid with hypertriglyceridemia because of lacking subcutaneous fat, leading to subsequent IR and $\beta$-cell dysfunction [20]. In a White European population, Navarro-Gonzalez et al. reported that the risk of developing diabetes was increased by $54 \%$ for per SD increase of TyG index, and the authors also suggested that TyG index was a better predictor of diabetes than TG or FBG separately [12].

In the subgroup analyses, we found that the positive relationship between TyG index and diabetes was more evident in elderly, women, obese or prediabetic individuals. The reasons could be explained as follows. Visceral adiposity tissue increases with age and may lead to the higher incidence and risk of diabetes [21]. In addition, the higher hepatocellular lipids in women may contribute to the increased risk of diabetes [22]. Moreover, a recent study showed that TyG was an important mediator in the BMI-related diabetes development in both obese and non-obese individuals [23]. Another retrospective study of 2,900 Korean adults reported that TyG index of 8.8 or higher significantly increased the risk of type 2 diabetes regardless of BMI range [13]. Finally, prediabetes is more likely related to IR than normoglycemia, which explains the more pronounced risk of developing diabetes in this population [24-26].

Several mechanisms have been reported to explain the predictive value of TyG index for the development of diabetes. On the one hand, increased TG level in the blood contributes to the inhibitory insulin activity, production of inflammatory cytokines, and muscle catabolism while overloaded TG in the pancreatic islet cells disrupts the $\beta$-cell function [27]. On the other hand, elevated glucose concentrations exert toxic effects on $\beta$-cells by raising reactive oxygen species [28]. These mechanisms have been confirmed in an intervention study indicating that the capacity of insulin secretion and IR status were improved by reduce TG and FBG level [29]. As the product of TG and FBG, high TyG index reveals both seriously decreased $\beta-$ cells and increased IR, which are considered to be the major events of incident diabetes [30]. Despite this, more mechanistic researches need to be conducted in different ethnic populations to reveal the difference and consistency of the role of TyG in the development of diabetes in order to better guide clinical practice.

Our findings have a few clinical implications. First, TyG index was recently reported to be superior to traditional predictors of IR and diabetes such as TG/HDL-C and HMOA-IR [31]. Second, several studies have shown that TyG index improved prediction of diabetes compared with FBG or TG itself, as well as single other lipid markers such as TC, LDL-C, and HDL-C cross different ethnic groups [12, 32, 33]. Third, TyG index is a simple, inexpensive and routine indicator and is suitable for clinical practice. Finally, and most importantly, monitoring the TyG index can help identify people at high risk of developing diabetes, even though their FBG or TG is not high or is at a borderline high level. For this group of people, timely lifestyle and diet adjustments are crucial [34].

\section{Study limitations}

The strength of the current research was to include a nationally representative sampling design, rigorous and standard protocol for data collection and follow-up, which made our results of prospective relationship more reliable. However, some limitations should be considered for cautious interpretation. 
First, despite we have fully adjusted for many risk factors, residual confounding might exist due to unrecognized confounders such as physical activity and family history of diabetes. Second, $2 \mathrm{~h}$ oral glucose tolerance test was not included to detect cases of diabetes, which might underestimate the incidence of diabetes. Third, the follow-up time was relatively short. Longer duration of follow-up is needed to further verify our results. Finally, all participants were Chinese people aged 45 years or older, caution should be made when interpreting our findings in younger individuals and in other ethnic populations.

\section{Conclusion}

In conclusion, TyG index was significantly and positively associated with risk of new-onset diabetes in middle-aged and elderly adults. TyG index might be a useful predictive marker for predicting new-onset diabetes.

\section{Abbreviations}

TyG, triglyceride glucose; TG, triglyceride; FBG, fasting blood glucose; BMI, body mass index. SBP, systolic blood pressure; DBP, diastolic blood pressure; CVD, cardiovascular disease

\section{Declarations}

\section{Acknowledgements}

We thank the Institute of Social Science Survey of Peking University and the National School of Development of Peking University for providing the data. We also acknowledge all the participants in the survey design and data collection as well as the CHARLS research team for collecting high-quality, nationally representative data.

\section{Authors' contributions}

Chao-lei CHEN, Yu-qing HUANG, and Ying-qing FENG designed the study, interpreted the data and contributed to critically revising the manuscript. Chao-lei CHEN and Lin-LIU analyzed the data and drafted the manuscript. Kenneth LO, Jia-yi HUANG, and Yu-ling YU helped manuscript editing and data analysis. All authors read and approved the final manuscript.

\section{Funding}

This work was supported by the Science and Technology Program of Guangzhou (No.201604020143, No.201604020018, No.201604020186, and No.201803040012), the National Key Research and Development Program of China (No.2017YFC1307603, No.2016YFC1301305), and the Key Area R\&D Program of Guangdong Province (No.2019B020227005).

\section{Availability of data and materials}


Detailed examination methods, questionnaire information, and mortality data can be referred to http://charls.pku.edu.cn/en.

\section{Ethics approval and consent to participate}

Our study complied with the Declaration of Helsinki and was approved by the Ethics Review Committee of Peking University.

\section{Consent for publication}

Not applicable.

\section{Competing Interests}

The authors declare that they have no conflicts of interest.

\section{Author details}

${ }^{1}$ Department of Cardiology, Guangdong Cardiovascular Institute, Guangdong Provincial Key Laboratory of Coronary Heart Disease Prevention, Guangdong Provincial People's Hospital, Guangdong Academy of Medical Sciences, Guangzhou, China

${ }^{2}$ Centre for Global Cardiometabolic Health, Department of Epidemiology, Brown University, Providence, USA

${ }^{3}$ Department of Applied Biology and Chemical Technology, The Hong Kong Polytechnic University, Hung Hom, Hong Kong, China

\section{References}

1. GBD 2016 Disease and Injury Incidence and Prevalence Collaborators 2017. Global, regional, and national incidence, prevalence, and years lived with disability for 328 diseases and injuries for 195 countries, 1990-2016: a systematic analysis for the Global Burden of Disease Study 2016. Lancet 390, 1211-59.

2. NCD Risk Factor Collaboration (NCD-RisC) 2016. Worldwide trends in diabetes since 1980: a pooled analysis of 751 population-based studies with 4.4 million participants. Lancet 387, 1513-30.

3. International Diabetes Federation. IDF Diabetes Atlas, 8th edition. Available from: http://www.diabetesatlas.org. accessed June 11, 2019.

4. Kahn SE 2003. The relative contributions of insulin resistance and beta-cell dysfunction to the pathophysiology of Type 2 diabetes. Diabetologia 46, 3-19.

5. Warram JH, Martin BC, Krolewski AS, Soeldner JS, Kahn CR 1990. Slow glucose removal rate and hyperinsulinemia precede the development of type II diabetes in the offspring of diabetic parents. Ann Intern Med 113, 909-15. 
6. Wang T, Lu J, Shi L, Chen G, Xu M, Xu Y, Su Q, Mu Y, Chen L, Hu R, et al. 2020. Association of insulin resistance and $\beta$-cell dysfunction with incident diabetes among adults in China: a nationwide, population-based, prospective cohort study. Lancet Diabetes Endocrinol 8, 115-24.

7. NCD Risk Factor Collaboration (NCD-RisC) 2016. Trends in adult body-mass index in 200 countries from 1975 to 2014: a pooled analysis of 1698 population-based measurement studies with $19 \cdot 2$ million participants. Lancet 387, 1377-96.

8. Kahn SE, Hull RL, Utzschneider KM 2006. Mechanisms linking obesity to insulin resistance and type 2 diabetes. Nature 444, 840-6.

9. Vasques AC, Novaes FS, de Oliveira Mda S, Souza JR, Yamanaka A, Pareja JC, Tambascia MA, Saad MJ, Geloneze B 2011. TyG index performs better than HOMA in a Brazilian population: a hyperglycemic clamp validated study. Diabetes Res Clin Pract 93, e98-e100.

10. Tohidi M, Baghbani-Oskouei A, Ahanchi NS, Azizi F, Hadaegh F 2018. Fasting plasma glucose is a stronger predictor of diabetes than triglyceride-glucose index, triglycerides/high-density lipoprotein cholesterol, and homeostasis model assessment of insulin resistance: Tehran Lipid and Glucose Study. Acta Diabetol 55, 1067-74.

11. Zhang M, Wang B, Liu Y, Sun X, Luo X, Wang C, Li L, Zhang L, Ren Y, Zhao Y, et al. 2017. Cumulative increased risk of incident type 2 diabetes mellitus with increasing triglyceride glucose index in normal-weight people: The Rural Chinese Cohort Study. Cardiovasc Diabetol 16, 30.

12. Navarro-González D, Sánchez-Íñigo L, Pastrana-Delgado J, Fernández-Montero A, Martinez JA 2016. Triglyceride-glucose index (TyG index) in comparison with fasting plasma glucose improved diabetes prediction in patients with normal fasting glucose: The Vascular-Metabolic CUN cohort. Prev Med 86, 99-105.

13. Lee DY, Lee ES, Kim JH, Park SE, Park CY, Oh KW, Park SW, Rhee EJ, Lee WY 2016. Predictive Value of Triglyceride Glucose Index for the Risk of Incident Diabetes: A 4-Year Retrospective Longitudinal Study. PLoS One 11, e0163465.

14. Mohd Nor NS, Lee S, Bacha F, Tfayli H, Arslanian S 2016. Triglyceride glucose index as a surrogate measure of insulin sensitivity in obese adolescents with normoglycemia, prediabetes, and type 2 diabetes mellitus: comparison with the hyperinsulinemic-euglycemic clamp. Pediatr Diabetes 17, 458-65.

15. Park B, Lee HS, Lee YJ 2020. Triglyceride glucose (TyG) index as a predictor of incident type 2 diabetes among non-obese adults: A 12-year longitudinal study of the Korean Genome and Epidemiology Study cohort. Transl Res.

16. Zhao Y, Hu Y, Smith JP, Strauss J, Yang G 2014. Cohort profile: the China Health and Retirement Longitudinal Study (CHARLS). Int J Epidemiol 43, 61-8.

17. Williams B, Mancia G, Spiering W, Agabiti Rosei E, Azizi M, Burnier M, Clement DL, Coca A, de Simone G, Dominiczak A, et al. 2018. 2018 ESC/ESH Guidelines for the management of arterial hypertension. Eur Heart J 39, 3021-104. 
18. Simental-Mendía LE, Rodríguez-Morán M, Guerrero-Romero F 2008. The product of fasting glucose and triglycerides as surrogate for identifying insulin resistance in apparently healthy subjects. Metab Syndr Relat Disord 6, 299-304.

19. American Diabetes Association 2020. 2. Classification and Diagnosis of Diabetes: Standards of Medical Care in Diabetes-2020. Diabetes Care 43, S14-S31.

20. Shulman GI 2014. Ectopic fat in insulin resistance, dyslipidemia, and cardiometabolic disease. $\mathrm{N}$ Engl J Med 371, 2237-8.

21. Machann J, Thamer C, Schnoedt B, Stefan N, Stumvoll M, Haring HU, Claussen CD, Fritsche A, Schick $F$ 2005. Age and gender related effects on adipose tissue compartments of subjects with increased risk for type 2 diabetes: a whole body MRI/MRS study. Magma 18, 128-37.

22. Greenman Y, Golani N, Gilad S, Yaron M, Limor R, Stern N 2004. Ghrelin secretion is modulated in a nutrient- and gender-specific manner. Clin Endocrinol (Oxf) 60, 382-8.

23. Low S, Khoo KCJ, Irwan B, Sum CF, Subramaniam T, Lim SC, Wong TKM 2018. The role of triglyceride glucose index in development of Type 2 diabetes mellitus. Diabetes Res Clin Pract 143, 43-49.

24. Meyer C, Pimenta W, Woerle HJ, Van Haeften T, Szoke E, Mitrakou A, Gerich J 2006. Different mechanisms for impaired fasting glucose and impaired postprandial glucose tolerance in humans. Diabetes Care 29, 1909-14.

25. Bock G, Chittilapilly E, Basu R, Toffolo G, Cobelli C, Chandramouli V, Landau BR, Rizza RA 2007. Contribution of hepatic and extrahepatic insulin resistance to the pathogenesis of impaired fasting glucose: role of increased rates of gluconeogenesis. Diabetes 56, 1703-11.

26. Faerch K, Borch-Johnsen K, Holst JJ, Vaag A 2009. Pathophysiology and aetiology of impaired fasting glycaemia and impaired glucose tolerance: does it matter for prevention and treatment of type 2 diabetes? Diabetologia 52, 1714-23.

27. Unger RH 1995. Lipotoxicity in the pathogenesis of obesity-dependent NIDDM. Genetic and clinical implications. Diabetes 44, 863-70.

28. Robertson RP, Harmon J, Tran PO, Poitout V 2004. Beta-cell glucose toxicity, lipotoxicity, and chronic oxidative stress in type 2 diabetes. Diabetes 53 Suppl 1, S119-24.

29. Leon-Acuña A, Alcala-Diaz JF, Delgado-Lista J, Torres-Peña JD, Lopez-Moreno J, Camargo A, GarciaRios A, Marin C, Gomez-Delgado F, Caballero J, et al. 2016. Hepatic insulin resistance both in prediabetic and diabetic patients determines postprandial lipoprotein metabolism: from the CORDIOPREV study. Cardiovasc Diabetol 15, 68.

30. Alejandro EU, Gregg B, Blandino-Rosano M, Cras-Méneur C, Bernal-Mizrachi E 2015. Natural history of $\beta$-cell adaptation and failure in type 2 diabetes. Mol Aspects Med 42, 19-41.

31. Lee SH, Kwon HS, Park YM, Ha HS, Jeong SH, Yang HK, Lee JH, Yim HW, Kang MI, Lee WC, et al. 2014. Predicting the development of diabetes using the product of triglycerides and glucose: the Chungju Metabolic Disease Cohort (CMC) study. PLoS One 9, e90430. 
32. Er LK, Wu S, Chou HH, Hsu LA, Teng MS, Sun YC, Ko YL 2016. Triglyceride Glucose-Body Mass Index Is a Simple and Clinically Useful Surrogate Marker for Insulin Resistance in Nondiabetic Individuals. PLoS One 11, e0149731.

33. Zheng S, Shi S, Ren X, Han T, Li Y, Chen Y, Liu W, Hou PC, Hu Y 2016. Triglyceride glucose-waist circumference, a novel and effective predictor of diabetes in first-degree relatives of type 2 diabetes patients: cross-sectional and prospective cohort study. J Transl Med 14, 260.

34. Lim EL, Hollingsworth KG, Aribisala BS, Chen MJ, Mathers JC, Taylor R 2011. Reversal of type 2 diabetes: normalisation of beta cell function in association with decreased pancreas and liver triacylglycerol. Diabetologia 54, 2506-14.

\section{Tables}

Table 1 Baseline characteristics of study participants according to quartiles of triglyceride glucose index 


\begin{tabular}{|c|c|c|c|c|c|}
\hline & Q1 & Q2 & Q3 & Q4 & $\begin{array}{l}P \text { - } \\
\text { value }\end{array}$ \\
\hline Number & 1857 & 1857 & 1857 & 1857 & \\
\hline Age, years & $59.56 \pm 9.83$ & $59.36 \pm 9.36$ & $59.60 \pm 9.12$ & $58.67 \pm 9.11$ & 0.008 \\
\hline Gender & & & & & $<0.001$ \\
\hline Male & $1007(54.2)$ & $921(49.6)$ & $782(42.1)$ & 747 (40.2) & \\
\hline Female & $850(45.8)$ & $936(50.4)$ & 1075 (57.9) & $1110(59.8)$ & \\
\hline Education & & & & & 0.338 \\
\hline $\begin{array}{l}\text { Primary school or } \\
\text { lower }\end{array}$ & 1325 (71.4) & 1307 (70.4) & $1332(71.7)$ & $1281(69.0)$ & \\
\hline Secondary school & 358 (19.3) & 362 (19.5) & $342(18.4)$ & $400(21.5)$ & \\
\hline Higher & $173(9.3)$ & $187(10.1)$ & $183(9.9)$ & $176(9.5)$ & \\
\hline Current married & 1639 (88.3) & $1644(88.5)$ & $1632(87.9)$ & $1649(88.8)$ & 0.843 \\
\hline Current smoking & 808 (43.5) & 753 (40.5) & $681(36.7)$ & $663(35.7)$ & $<0.001$ \\
\hline Current drinking & $548(29.5)$ & $498(26.8)$ & 403 (21.7) & $441(23.7)$ & $<0.001$ \\
\hline SBP, mmHg & $\begin{array}{l}126.70 \pm \\
21.07\end{array}$ & $\begin{array}{l}128.29 \pm \\
20.75\end{array}$ & $\begin{array}{l}131.30 \pm \\
22.03\end{array}$ & $\begin{array}{l}133.00 \pm \\
21.63\end{array}$ & $<0.001$ \\
\hline DBP, mmHg & $73.69 \pm 12.10$ & $74.59 \pm 11.96$ & $76.34 \pm 12.40$ & $77.70 \pm 12.52$ & $<0.001$ \\
\hline $\mathrm{BMI}, \mathrm{kg} / \mathrm{m}^{2}$ & $22.01 \pm 3.18$ & $22.83 \pm 3.73$ & $23.61 \pm 3.67$ & $24.78 \pm 3.67$ & $<0.001$ \\
\hline WC, $\mathrm{cm}$ & $80.06 \pm 10.74$ & $82.55 \pm 11.74$ & $84.59 \pm 12.75$ & $87.71 \pm 12.49$ & $<0.001$ \\
\hline $\mathrm{TC}, \mathrm{mg} / \mathrm{dL}$ & $\begin{array}{l}178.15 \pm \\
33.52\end{array}$ & $\begin{array}{l}188.61 \pm \\
33.88\end{array}$ & $\begin{array}{l}196.85 \pm \\
36.74\end{array}$ & $\begin{array}{l}205.84 \pm \\
39.63\end{array}$ & $<0.001$ \\
\hline $\mathrm{TG}, \mathrm{mg} / \mathrm{dL}$ & $59.72 \pm 13.51$ & $86.81 \pm 13.01$ & $\begin{array}{l}121.10 \pm \\
18.03\end{array}$ & $\begin{array}{l}217.93 \pm \\
88.01\end{array}$ & $<0.001$ \\
\hline LDL-C, mg/dL & $\begin{array}{l}107.93 \pm \\
29.13\end{array}$ & $\begin{array}{l}117.54 \pm \\
30.86\end{array}$ & $\begin{array}{l}124.06 \pm \\
33.99\end{array}$ & $\begin{array}{l}118.19 \pm \\
39.17\end{array}$ & $<0.001$ \\
\hline HDL-C, mg/dL & $60.47 \pm 14.97$ & $55.65 \pm 13.98$ & $50.28 \pm 12.89$ & $42.27 \pm 11.38$ & $<0.001$ \\
\hline $\mathrm{FBG}, \mathrm{mg} / \mathrm{dL}$ & $93.57 \pm 13.31$ & $99.16 \pm 10.40$ & $\begin{array}{l}101.03 \pm \\
10.40\end{array}$ & $106.14 \pm 9.98$ & $<0.001$ \\
\hline Hemoglobin A1c, \% & $5.05 \pm 0.38$ & $5.08 \pm 0.39$ & $5.11 \pm 0.41$ & $5.16 \pm 0.40$ & $<0.001$ \\
\hline TyG index & $7.90 \pm 0.25$ & $8.35 \pm 0.10$ & $8.70 \pm 0.11$ & $9.29 \pm 0.33$ & $<0.001$ \\
\hline Hypertension & $568(30.8)$ & $652(35.5)$ & $784(42.7)$ & $888(48.2)$ & $<0.001$ \\
\hline Cardiovascular & $197(10.6)$ & $233(12.6)$ & $249(13.5)$ & $265(14.3)$ & 0.006 \\
\hline
\end{tabular}




\begin{tabular}{|llllll|}
\hline disease & & & & \\
\hline Lipid-lowering drugs & $34(1.8)$ & $52(2.8)$ & $76(4.1)$ & $107(5.8)$ & $<0.001$ \\
\hline New-onset diabetes & $123(6.6)$ & $166(8.9)$ & $232(12.5)$ & $270(14.5)$ & $<0.001$ \\
\hline
\end{tabular}

Data are presented as mean \pm standard deviation or number (\%).

$\mathrm{Q}$, quartiles; SBP, systolic blood pressure; DBP, diastolic blood pressure; BMI, body mass index; WC, waist circumference; TC, total cholesterol; TG, triglyceride; LDL-C, low-density lipoprotein cholesterol; HDL-C, high-density lipoprotein cholesterol; FBG, fasting blood glucose; TyG, triglyceride glucose.

Table 2 Comparison of baseline characteristics of study participants who developed diabetes or not 


\begin{tabular}{|c|c|c|c|c|}
\hline & Overall & Not developed DM & Developed DM & $P$-value \\
\hline Number & 7428 & 6637 & 791 & \\
\hline Age, years & $59.30 \pm 9.36$ & $59.14 \pm 9.37$ & $60.68 \pm 9.20$ & $<0.001$ \\
\hline Gender & & & & 0.210 \\
\hline Male & $3457(46.5)$ & $3106(46.8)$ & $351(44.4)$ & \\
\hline Female & $3971(53.5)$ & $3531(53.2)$ & $440(55.6)$ & \\
\hline Education & & & & 0.018 \\
\hline Primary school or lower & $5245(70.6)$ & $4656(70.2)$ & $589(74.6)$ & \\
\hline Secondary school & $1462(19.7)$ & 1319 (19.9) & $143(18.1)$ & \\
\hline Higher & $719(9.7)$ & $661(10.0)$ & $58(7.3)$ & \\
\hline Current married & $6564(88.4)$ & $5888(88.7)$ & $676(85.5)$ & 0.008 \\
\hline Current smoking & $2905(39.1)$ & $2595(39.1)$ & $310(39.2)$ & 0.993 \\
\hline Current drinking & $1890(25.4)$ & $1709(25.7)$ & $181(22.9)$ & 0.088 \\
\hline SBP, mmHg & $129.82 \pm 21.51$ & $129.29 \pm 21.42$ & $134.25 \pm 21.78$ & $<0.001$ \\
\hline DBP, mmHg & $75.58 \pm 12.34$ & $75.29 \pm 12.24$ & $77.98 \pm 12.92$ & $<0.001$ \\
\hline $\mathrm{BMI}, \mathrm{kg} / \mathrm{m}^{2}$ & $23.31 \pm 3.71$ & $23.16 \pm 3.62$ & $24.52 \pm 4.23$ & $<0.001$ \\
\hline WC, $\mathrm{cm}$ & $83.72 \pm 12.28$ & $83.31 \pm 12.13$ & $87.18 \pm 12.94$ & $<0.001$ \\
\hline $\mathrm{TC}, \mathrm{mg} / \mathrm{dL}$ & $192.36 \pm 37.44$ & $191.85 \pm 37.38$ & $196.62 \pm 37.70$ & 0.001 \\
\hline $\mathrm{TG}, \mathrm{mg} / \mathrm{dL}$ & $121.39 \pm 75.40$ & $119.39 \pm 73.93$ & $138.21 \pm 84.99$ & $<0.001$ \\
\hline LDL-C, mg/dL & $116.93 \pm 34.00$ & $116.63 \pm 33.98$ & $119.46 \pm 34.07$ & 0.027 \\
\hline $\mathrm{HDL}-\mathrm{C}, \mathrm{mg} / \mathrm{dL}$ & $52.17 \pm 14.98$ & $52.46 \pm 14.87$ & $49.74 \pm 15.68$ & $<0.001$ \\
\hline $\mathrm{FBG}, \mathrm{mg} / \mathrm{dL}$ & $99.98 \pm 11.98$ & $99.54 \pm 11.84$ & $103.65 \pm 12.47$ & $<0.001$ \\
\hline Hemoglobin A1c, \% & $5.10 \pm 0.40$ & $5.08 \pm 0.39$ & $5.25 \pm 0.44$ & $<0.001$ \\
\hline TyG index & $8.56 \pm 0.56$ & $8.54 \pm 0.55$ & $8.72 \pm 0.56$ & $<0.001$ \\
\hline Hypertension & $2892(39.3)$ & $2483(37.7)$ & $409(52.1)$ & $<0.001$ \\
\hline Cardiovascular disease & $944(12.8)$ & $807(12.2)$ & $137(17.4)$ & $<0.001$ \\
\hline Lipid-lowering drugs & $269(3.6)$ & $222(3.3)$ & $47(5.9)$ & $<0.001$ \\
\hline
\end{tabular}

Data are presented as mean \pm SD or $n(\%)$. 
Q, quartiles; SBP, systolic blood pressure; DBP, diastolic blood pressure; BMI, body mass index; WC, waist circumference; TC, total cholesterol; TG, triglyceride; LDL-C, low-density lipoprotein cholesterol; HDL-C, high-density lipoprotein cholesterol; FBG, fasting blood glucose; TyG, triglyceride glucose.

Table 3 Cox-proportional hazard models for the association between triglyceride glucose index and incident diabetes

\begin{tabular}{|cllll|}
\hline & Case/total & Model 1 & Model 2 & Model 3 \\
\hline TyG index & & & & \\
\hline Per SD increase & & $1.34(1.25,1.43)$ & $1.35(1.26,1.44)$ & $1.22(1.14,1.31)$ \\
\hline Quartiles & & & & \\
\hline Q1 & $123 / 1857$ & ref & ref & ref \\
\hline Q2 & $166 / 1857$ & $1.37(1.08,1.73)$ & $1.37(1.08,1.73)$ & $1.22(0.96,1.54)$ \\
\hline Q3 & $232 / 1857$ & $1.91(1.54,2.38)$ & $1.90(1.53,2.37)$ & $1.61(1.28,2.01)$ \\
\hline Q4 & $270 / 1857$ & $2.27(1.84,2.81)$ & $2.32(1.87,2.87)$ & $1.73(1.38,2.16)$ \\
\hline Pfor trend & & $<0.001$ & $<0.001$ & $<0.001$ \\
\hline
\end{tabular}

Data are presented as hazard ratio (95\% confident interval). TyG, triglyceride glucose; SD, standard deviation; Q, quartiles.

Model 1 adjust for none.

Model 2 adjust for age and gender.

Model 3 adjust for age, gender, education, marriage, smoking, drinking, body mass index, waist circumference, systolic blood pressure, history of hypertension, history of cardiovascular disease, and usage of lipid-lowering drugs.

Table 4 Multivariable-adjusted hazard ratios for the association between quartiles of triglyceride glucose index and incident diabetes by subgroups 


\begin{tabular}{|c|c|c|c|c|c|c|c|}
\hline & Case/total & Q1 & Q2 & Q3 & Q4 & $\begin{array}{l}P \text { for } \\
\text { trend }\end{array}$ & $\begin{array}{l}P \text { for } \\
\text { interaction }\end{array}$ \\
\hline Age, years & & & & & & & 0.74 \\
\hline$\geq 65$ & $258 / 2029$ & ref & $\begin{array}{l}1.22 \\
(0.81 \\
1.83)\end{array}$ & $\begin{array}{l}1.66 \\
(1.13 \\
2.43)\end{array}$ & $\begin{array}{l}1.82 \\
(1.23 \\
2.69)\end{array}$ & $<0.001$ & \\
\hline$<65$ & $533 / 5399$ & ref & $\begin{array}{l}1.20 \\
(0.89 \\
1.61)\end{array}$ & $\begin{array}{l}1.55 \\
(1.17 \\
2.05)\end{array}$ & $\begin{array}{l}1.66 \\
(1.26, \\
2.19)\end{array}$ & $<0.001$ & \\
\hline Gender & & & & & & & 0.14 \\
\hline Male & $351 / 3457$ & ref & $\begin{array}{l}1.15 \\
(0.84 \\
1.58)\end{array}$ & $\begin{array}{l}1.33 \\
(0.97 \\
1.82)\end{array}$ & $\begin{array}{l}1.56 \\
(1.14 \\
2.14)\end{array}$ & 0.004 & \\
\hline Female & $440 / 3971$ & ref & $\begin{array}{l}1.34 \\
(0.93 \\
1.94)\end{array}$ & $\begin{array}{l}1.96 \\
(1.40 \\
2.75)\end{array}$ & $\begin{array}{l}1.99 \\
(1.42 \\
2.79)\end{array}$ & 0.001 & \\
\hline BMI, $\mathrm{kg} / \mathrm{m}^{2}$ & & & & & & & 0.66 \\
\hline$\geq 24$ & $405 / 2822$ & ref & $\begin{array}{l}1.53 \\
(1.01 \\
2.33)\end{array}$ & $\begin{array}{l}1.85 \\
(1.25 \\
2.74)\end{array}$ & $\begin{array}{l}2.03 \\
(1.39 \\
2.97)\end{array}$ & $<0.001$ & \\
\hline$<24$ & $377 / 4493$ & ref & $\begin{array}{l}1.08 \\
(0.80 \\
1.46)\end{array}$ & $\begin{array}{l}1.55 \\
(1.17 \\
2.06)\end{array}$ & $\begin{array}{l}1.63 \\
(1.20 \\
2.21)\end{array}$ & $<0.001$ & \\
\hline Glycemic status & & & & & & & 0.41 \\
\hline Normoglycemia & $528 / 3888$ & ref & $\begin{array}{l}1.16 \\
(0.82 \\
1.63)\end{array}$ & $\begin{array}{l}1.54 \\
(1.12 \\
2.11)\end{array}$ & $\begin{array}{l}1.38 \\
(1.01, \\
1.89)\end{array}$ & 0.03 & \\
\hline Prediabetes & $263 / 3540$ & ref & $\begin{array}{l}1.17 \\
(0.84, \\
1.65)\end{array}$ & $\begin{array}{l}1.35 \\
(0.95 \\
1.90)\end{array}$ & $\begin{array}{l}1.80 \\
(1.25, \\
2.60)\end{array}$ & 0.002 & \\
\hline
\end{tabular}

Data are presented as hazard ratio (95\% confident interval). Q, quartiles; BMI, body mass index.

Models adjust for age, gender, education, marriage, smoking, drinking, body mass index, waist circumference, systolic blood pressure, history of hypertension, history of cardiovascular disease, and usage of lipid-lowering drugs except the subgroup variable itself.

\section{Figures}




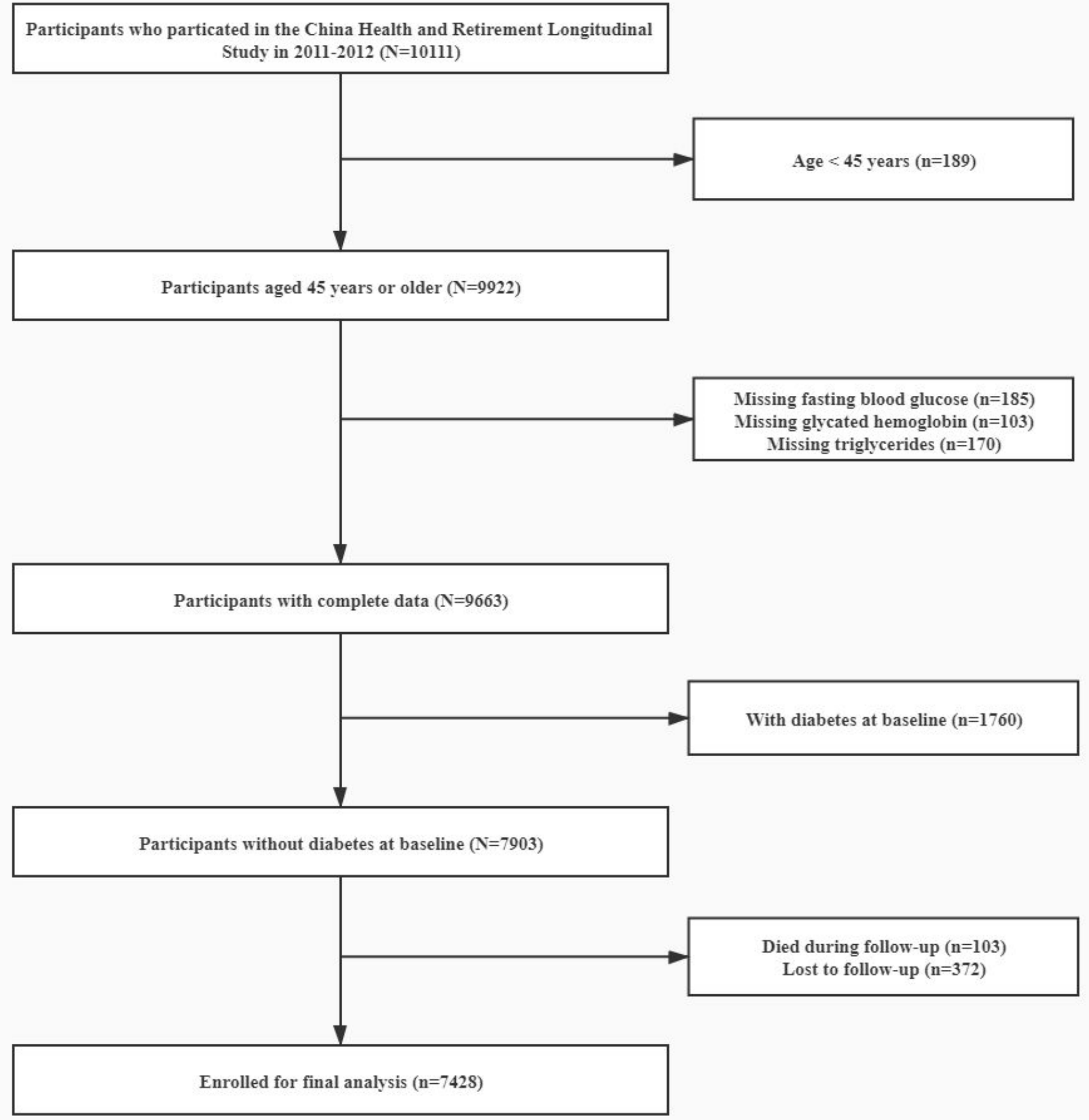

Figure 1

Flow chart of study participants. 


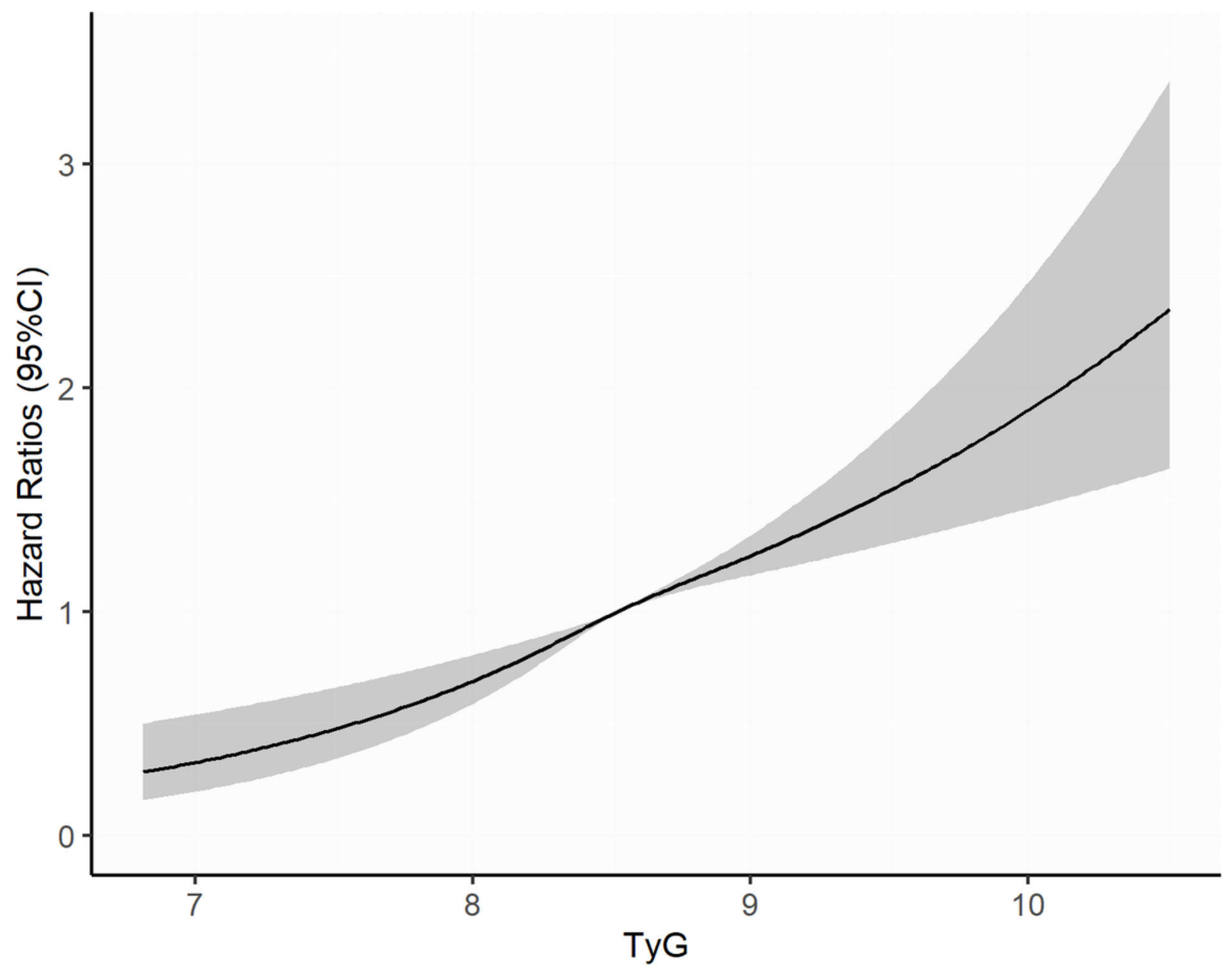

Figure 2

Adjusted cubic spline model of the association between triglyceride glucose index and risk of new-onset diabetes. TyG, triglyceride glucose. 